\title{
Parental involvement and learners' performance in rural basic schools of Zambia
}

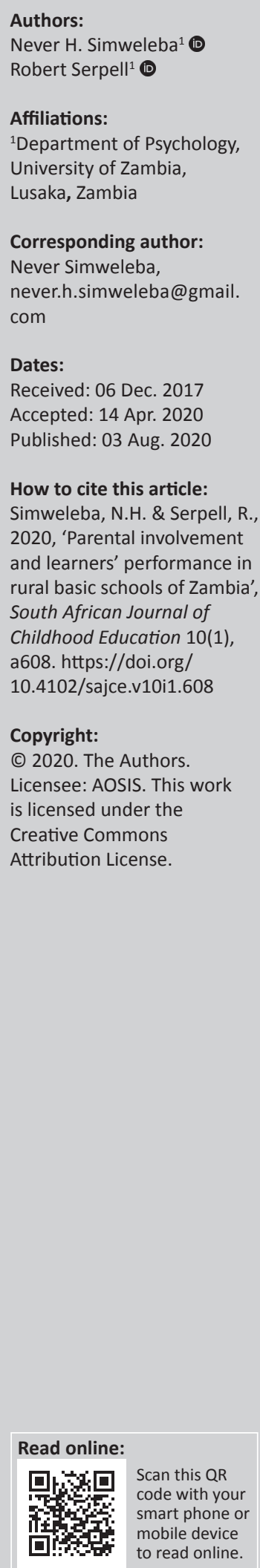

Background: Parental involvement is one of the important factors in pupils' academic achievement.

Aim: The study sought to assess whether an intervention to enhance the interaction of parents with Grade 4 learners (aged 10-15 years) in homework would improve the learners performance in Chitonga and Mathematics.

Setting: This study was conducted with two rural primary schools in the Kalomo District of Southern Province, Zambia.

Methods: The participants were Grade 4 learners and their parents. A total of 168 participants were enlisted (84 learners and 84 parents). Elementary tests in Mathematics and Chitonga, the quality of parent-child interaction in homework, the quality and frequency of parent-school communication in homework, and the use of home resources in the instruction of children to increase Chitonga and Mathematics skills were assessed. One school served as a control while the other was the target of intervention. Parents in the intervention group received a 10-week programme of sensitisation on how to support their children in homework using available local resources and on parent-child interactions. Questionnaires and interviews were sent to collect data from parents while tests in Mathematics and Chitonga, systematically developed by the national regulatory body, were set to assess the learners' performance.

Results: Post-test scores of learners in Mathematics and Chitonga in the intervention school were significantly higher, in addition to increased parent-child interaction and the use of home resources in instruction.

Conclusion: The authors conclude that interventions which empower parents with knowledge and skills for greater involvement in their children's homework can be effective in improving the learners' performance.

Keywords: rural communities; parental involvement; academic performance; homework; home-school communication; home learning resources; parent-child interaction.

\section{Introduction}

Formal education, through school enrolment in the childhood years, is widely recognised across the contemporary world as a key ingredient of three complementary agendas: 'the promotion of economic progress, the transmission of culture from one generation to the next, and the cultivation of children's intellectual and moral development' (Serpell 1993:1). In Zambia and in many other African countries, nominal enrolment in schooling has increased dramatically over the past 50 years. But the outcomes are disappointing on several fronts, especially in rural areas, where economic productivity remains low and academic achievement statistics show that many children complete several years of schooling without mastering the basic curriculum (Hungi 2011). The minority who succeed are expected to progress up a narrowing staircase of educational opportunity and seldom return to contribute to the economic and cultural life of their rural community of origin (Serpell 1999).

Whatever the historical origins of this situation or the policy options for improving it, for the majority of children enrolled in the lower grades, school teachers and parents in rural African communities face a challenge of mutual credibility regarding the reciprocal relevance of what is taught in school and the demands of local economic and cultural life. Children who begin to appropriate literacy in the early grades of elementary school can only be regarded as educational success stories if they grow up to experience what they have learned as enhancing their quality of life and that of their society ... If the agenda of schools is perceived by parents as hostile or irrelevant to their goals, or by students as threatening to their sense of personal or social identity, any claims that literacy has empowered them must be dismissed as fraudulent. (Serpell 1997:610) 
Studies by Ng'asike (2014) in Kenya and by Ngwaru (2014) in Zimbabwe and Tanzania have articulated in detail how the indigenous cultures are rich in opportunities for children's acquisition of perceptual and cognitive skills. Traditionally, children may have acquired those skills through intentional participation with little or no explicit instruction. 'Learning through keen observation and listening, in anticipation of participation, seems to be especially valued and emphasized in communities where children have access to learning from informal community involvement' (Rogoff et al. 2003:175). This is a feature of the ecocultural niche of child development in many rural African societies. Moreover, studies in Brazil, amongst low-income urban children with low levels of academic achievement, have found that such children often display higher levels of arithmetical competence using cognitive strategies quite different from the algorithms taught in schools (Nunes, Schliemann \& Carraher 1993). In a similar vein, Ng'asike's (2014) reconceptualist study in Kenya showed that even preschool early childhood education tends to neglect the educational potential of home resources in a rural Turkana community. Children spend most of their time outside their school or in areas near their homes, and have a rich source of learning materials at their disposal for acquiring quantitative skills like counting, addition, division, multiplication and subtraction. Serpell and Marfo (2014) state:

In rural communities, many of the adult parents of children enrolled in local early childhood education centres and primary schools have deep and confident expertise in such 'funds of knowledge' (Moll \& Greenberg 1990). According to Bronfenbrenner's (1979) systemic perspective, the quality of social relations between teachers and parents is a key factor in determining how the child develops within a multilevel ecological system. In Arizona, United States of America (USA), Moll et al. (1992) have described a programme of building strategic connections between the regular household practices of low-income, working-class Mexican-origin communities and classroom instruction in mainstream elementary schools. But, instead of collaborating to generate a synergy between their respective bodies of expertise, parents and teachers in rural African settings often seem to conspire to exclude such curriculum enrichment opportunities from the scope of their programmatic interactions. They focus instead on discussing school success in terms of its external facets as a mode of access to secondary school, which in turn is construed instrumentally as a route for obtaining credentials to deploy in the formal sector labour-market. Both groups fail to recognise, let alone capitalize on, the culturally embedded funds of knowledge that are increasingly being identified by scholars as critical assets in any effort to (a) enhance learning by infusing locally compatible learning modes into instruction and (b) make learning meaningful by expanding curricular content to include content with local relevance. (p. 141)

Extensive research has been published on the value of strengthening home-school connections in affluent industrialised countries (e.g. Epstein 2001; Seginer 2006), and successive federal governments in the USA have increasingly endorsed it as an integral part of public educational policy. However, drawing lessons relevant to rural Africa from the experience of such programmes is challenging, as the wider context of educational policy and resources is very different even when the programmes are explicitly focused on low-income, low-literacy communities. Moreover, the particular value of a given activity for mediating home-school connections is likely to vary in accordance with the local perceptions of parents and teachers based on their respective roles and competencies. Seginer (2006) noted in an ecologically informed review of multiple studies of parental involvement that:

$[A] \mathrm{s}$ children move from kindergarten and elementary to junior and high school, parents judge themselves less able to help with school subjects ... and their involvement is limited mainly to motivation prompting. (p. 27)

In Kenya, a survey of teachers at 30 schools in one district found a significant positive correlation between the reported extent of parental involvement in the homework assigned to their children by their schools and the academic outcomes at the end of primary school (Echaune, Ndiku \& Sang 2015). The practice of setting homework assignments is an established instructional routine in Zambia's public educational curriculum. Yet in a survey of parents and teachers at six rural public primary schools in Zambia's Central Province, only one in four parents interviewed indicated that they helped their children with their schoolwork (Musonda 2011). In Singapore, Ho (2007) successfully conducted parent education workshops across a wide range of family socio-economic conditions, designed to foster parental involvement in children's pre-primary Mathematics homework.

The small-scale intervention project described in this paper was conducted in Kalomo, a predominantly rural, Tongaspeaking district of Zambia, as a strategic response to the district's relatively low profile of academic achievement over the past 3 years. The design of the intervention drew qualitative inspiration from the success of Ho's (2007) parent education project in generating significant gains in children's early mathematical attainment, by involving parents in the school's homework assignments. While many interventions to enhance parent participation in their children's homework use the expression 'parent training', we prefer the term 'sensitisation', which is widely used in social programming in Zambia. The communication with parents in the intervention is construed by them as respectfully acknowledging their current practices as grounded in their personal experience and local cultural expertise, while seeking to raise their awareness of new practices and sensitising them to their potential benefits.

Our guiding hypotheses were that parental involvement would improve the academic performance of learners in Mathematics and Chitonga, and more specifically that the sensitisation of parents would increase parent-child interaction in children's homework; increased home-school communication would improve the academic performance of learners in Mathematics and Chitonga; and sensitisation of parents in the use of home resources would result in improved academic performance of learners in Mathematics and Chitonga. More broadly, the goal was to demonstrate 
the feasibility and effectiveness of deploying a modest extension of educational practices, in an economically marginalised community, to generate a synergistic collaboration between children's homes and schools and thereby contribute positively to the cultivation of children's intellectual development.

\section{Research methods and design Study design and setting}

The study adopted a quasi-experimental design using quantitative methods, supplemented by informal qualitative observations. While the learners exposed to the intervention and control treatments were not randomly selected, the groups were recruited from two rural schools with very similar sociocultural conditions, and the equivalence of their academic achievement profiles was established with pre-testing on the dependent variables before the intervention. Further control of extraneous variation was exercised by focusing statistical analysis on difference scores between each participant's pre- and post-test scores. Qualitative analysis of children's and parents' testimonies helped to provide a deeper understanding of the experience of research participants in their natural environments (Yoshikawa et al. 2008).

The intervention was conducted with Grade 4 learners enrolled at two government primary schools in the Kalomo District, Zambia. Kalomo is a predominantly rural district of Zambia, with a population in 2010 of 258570 , a density of 17.2 per square kilometre, a sex ratio of 94.7 males per 100 females, and an age dependency ratio of 113.5 (Central Statistical Office [CSO] 2014). Chitonga (the most widely spoken language of communication in Southern Province) was reported as such by $95 \%$ of Kalomo residents in the 2010 census. Of the adult population, $82.5 \%$ claimed to be literate. In rural areas of Southern Province as a whole, $87 \%$ of children between the ages of 7 and 13 were attending school at the extent of $89 \%$ in the Kalomo District. Between 2000 and 2010, the net primary attendance rate for males increased from $64.7 \%$ to $76.9 \%$ and from $66.3 \%$ to $78.2 \%$ for females (CSO 2014:25). The Examinations Council of Zambia (ECZ) conducts an annual nationwide standardised examination for learners completing primary Grade $7 .{ }^{1}$ In 2015 , the mean performance (605, standard error [s.e.] 0.90) across six learning areas by candidates in the Kalomo District was below the national mean (611, s.e. 0.13) and comparable to that of other predominantly rural districts of the province (Examinations Council of Zambia (ECZ), 2016).

\section{Study population and sampling strategy}

The study population was Grade 4 learners in the Kalomo District, Southern Province, Zambia, aged 10-15 years, and their parents. The sample consisted of 168 participants:

1.The Grade 7 Composite Examination covers six subjects, namely English, Mathematics, Soial and Deviopmint Studies, in subs, namely English, Mathematics, Social and Development Studies, Integrated Science, Creative and Technology Studies, and Zambian Languages. In addition, the examination has two intelligence tests, also known as Special Paper 1 (Verbal Reasoning) and Specia Paper 2 (Non-verbal Reasoning). Scores are standardised, yielding a minimum score of 50 and a maximum of 150 for each learning area.
84 parents (39 females and 45 males) and 84 learners (43 females and 41 males) drawn from two government schools. For convenience of access, and were considered typical of rural government schools in the district, schools were selected by the researcher Never Hantuba Simweleba (NHS), who has several years of experience as a government primary school teacher in the district (but had no prior professional or personal connection to either school). Both schools were situated in rural areas at some distance from the nearest town centre, although the intervention school was more remote. After a preliminary visit to each school, permission was sought from the office of the District Education Board Secretary (DEBS) who provided an introduction letter to the head teachers authorising the project and requesting cooperation. The head teachers of the two schools wrote letters to the parents informing them of and inviting them to a meeting where the purpose and procedures of the study were explained, after which parents signed consent forms and the children signed assent forms. All of the parents contacted responded positively and gave their consent. Within each school, learners were selected using simple random sampling of names on the class register of each class. Parents of the pupils who were selected from the sampled schools automatically qualified to take part in the study.

\section{Intervention}

The design of the intervention was based on exploratory inquiries by the researcher to establish the perceptions of both parents and teachers on existing constraints on the quality of home-school relations. At the intervention school, parents were sensitised to identifying and integrating local resources with what pupils learnt at school. The interactions between facilitators and parents were conducted mainly in English with fluid switching into Chitonga in accordance with prevailing social linguistic norms in Zambia. This ensured that any technical terms were translated and explained in Chitonga, the language of everyday discourse in most of the parents' homes. Parents and teachers at the control school were not sensitised in any way. They answered the questionnaires based on what the questions required them to answer.

The intervention was spread over a period of 10 weeks beginning with a 2-day workshop, held at the school on 2 consecutive days at which meals were provided. The workshop programme was drawn up in collaboration with three of the school's serving class teachers (all women) and the head teacher. It was conducted by the researcher in collaboration with three teachers who were recruited from staff of the school and trained by the researcher as facilitators. The class teacher of the intervention group did not participate in the workshop. Forty-two parents or family caregivers attended (of whom 17 were female while 25 were male).

The workshop focused on sensitising participants to the many benefits of parent involvement for students, the school and the community and raising their awareness of practical 
methods and strategies for promoting it. The following sequence of topics was followed across sessions that included lecture presentations, group discussions and hands-on activities: partnership between parents and teachers; recognising what parents are already doing; teachers' expectations of parents; parents' expectations of teachers; homework (how to help, challenges); different types of communication (value of regular, two-way, meaningful communication between schools and families); the importance of learning at home; how parents can be involved; and homes as learning resources (things that can be used to learn at home, learning activities in the home, ways children can be assisted in the home). During the workshop, parents were put in groups to perform activities relating to assisting their children with schoolwork. Individual participants presented their work and facilitators and other participants provided feedback. A summary of the guidelines for facilitators is presented in Appendix 1.

Sensitisation at the workshop included examples of concrete homework activities to enhance children's learning through the use of home materials and activities as learning resources for Mathematics and Chitonga. For instance, in Mathematics the focus was on using different sizes of containers to measure liquids such as water and milk, for weighing, measuring, adding, subtracting and dividing. Activities included using containers of different measurements such as $750 \mathrm{~mL}, 2.5 \mathrm{~L}, 5 \mathrm{~L}$ and $20 \mathrm{~L}$ when parents are handling liquids and weighing different items using empty plastics such as one which contained sugar. In cooking activities, the cutting of tomatoes during cooking was considered to be a good practice in Mathematics under the topic of fractions. As the area of study was a farming zone, the selling of products was another important aspect concerning calculations. Maize stalks were used for division in Mathematics. For Chitonga, the focus was on drawing, naming, making words and spelling different things in the home and local environment.

After the training and the administration of the first parent questionnaire, during the 10 -week period of the project (June-August 2016), the researcher made follow-up visits to parental homes with two teachers from the school who were familiar with the district. Reports were collected on what parents implemented in their daily activities and interactions with their children. At the end of the period, the parents' questionnaire was administered again to assess whether or not the intervention worked.

\section{Data collection and analysis}

Data were collected through questionnaires, interviews, focus group discussions, and pre- and post-tests in Mathematics and Chitonga. Quantitative data were entered into the Statistical Package for Social Sciences (SPSS). Before analysis it was reviewed to ensure consistency and accuracy by verifying it with the hard copy questionnaire. Data were further subjected to testing for internal validity and also to check for extreme outliers. Quantitative data were analysed with statistical techniques of analysis of variance
(ANOVA), $t$-test, Mann-Whitney U test and Cronbach's alpha test of reliability.

\section{Parent questionnaire}

The questionnaire was designed by the researcher and comprised questions about the respondent's demographic characteristics and about the frequency of her/his involvement in home activities, homework and communication with the school. Most items were in a multiple-choice format and were scored on a five-point scale with opinions ranging from strongly agree to strongly disagree. Some of the items were:

- How often do you help your child with homework?

- How many times a month do you listen to your child read?

- How much time do you spend per session in helping your child?

- How regularly do you communicate with teachers?

- What are your views on the frequency of homework?

Three scales were constructed for the analysis of responses, by 84 parents, to the questionnaire: Homework (six items, Cronbach's alpha 0.72) home-school communication (17 items, alpha 0.70) and home resources (eight items, alpha 0.77). Overall, the internal consistency of responses to the questionnaire $(31$ items) was high (alpha $=0.86)$. Parents responded to the questionnaire in writing at their own convenience and could choose to respond to the English version or to a translated version in the main local language of Chitonga, prepared by the researcher, who is a firstlanguage speaker of Chitonga, with approval from the Research Ethics Committee. Parents who expressed difficulty with reading or understanding the text of the questionnaire were assisted by the researcher with oral interpretation. (Full details of the questionnaire are presented in Appendices A and B of Simweleba, 2017.)

\section{Informal interviews and focus group discussions}

In addition to the structured questionnaire, a number of informal interviews were conducted with parents during visits to their homes and two focus group discussions were held to explore insights and concerns amongst learners and their parents. Oral testimony in interviews and focus group discussions were tape-recorded and transcribed, reviewed by the researcher, discussed with an independent local informant for clarification of meaning, and examined qualitatively in search of evidence about how much of an impact the participating parents observed as a result of the intervention programme on their own interactions with their child at home, and on their child's academic progress and growth of social responsibility.

\section{Children's academic performance measures}

Children wrote the Chitonga and Mathematics tests at the beginning and end of term 2 . The pre- and post-tests were designed by the researcher to reflect the content of the current syllabus followed by the schools. They were pilot tested and evaluated in accordance with the criteria for other standardised 
examinations by the ECZ, which is the statutory examining body for all the public educational examinations in the national school system. Each test comprised 25 items with a time limit of $1 \mathrm{~h}$. Item analysis revealed a range of $0.2-0.8$ on the difficulty index scale of $0-1$, representing the proportion of students who answered each test item accurately, which was considered acceptable. Learners wrote the tests in Mathematics and Chitonga in their classroom without the teacher's assistance.

\section{Ethical consideration}

The research received approval from the Humanities and Social Sciences Research Ethics Committee (HSSREC) of the University of Zambia on 09/02/2016.

The researcher adhered to all ethical considerations in order to build trust and respect with the participants. Approval was given before the data collection commenced. The Government Ministry of Education Permanent Secretary's office and the DEBS also allowed the researcher to conduct the study. A participant information sheet, and consent and assent forms were prepared and the purpose of the study was clearly explained to participants before signing. The translation of the forms from English to Chitonga was approved by University of Zambia Research Ethics Committee (UNZAREC). Participation was voluntary and participants were free to withdraw at any time if they felt like doing so. Only participants who signed the forms were recruited to the study. The researcher also sought their permission orally to photograph some of their activities relating to homework, and it was explained that these were purely for the study. No names of participants were discussed in the study. All primary project records were kept under lock and key.

\section{Results}

A summary of the pre- and post-test scores for the control and intervention schools are shown in Table 1.

A paired sample $t$-test showed that for the control school there were no significant changes between the Chitonga pre- and post-test scores $(t[41]=-1.750, p=0.088)$, or between the Mathematics pre- and post-scores $(t[41]=0.510, p=0.613)$. On the other hand, for the intervention school, the post-test scores in Chitonga were significantly higher than the pre-test scores $(t[41]=-4.465, p<0.001)$, and the Mathematics posttest scores were significantly higher than the pre-test scores $(t[41]=6.205, p<0.001)$.

An independent samples $t$-test (Table 2) was used to determine whether there were significant differences between the scores of boys and girls. The pre-test scores in Chitonga for girls (mean $[\mathrm{M}]=11.1$, standard deviation $[\mathrm{SD}]=4.05)$ were similar to those of boys $(\mathrm{M}=10.5, \mathrm{SD}=4.03),(t[82]=0.739, p=0.462)$. The post-test scores in Chitonga for girls $(\mathrm{M}=12.9, \mathrm{SD}=6.36)$ and boys $(\mathrm{M}=10.7, \mathrm{SD}=4.16), t(72.77)=1.864, p=0.066$ were also similar. The mean scores of girls in the Mathematics pretest $(\mathrm{M}=9.6, \mathrm{SD}=3.55)$ were similar to those of boys $(\mathrm{M}=9.1$, $\mathrm{SD}=3.76),(t[82]=0.608, p=0.545)$ and the post-test scores for
TABLE 1: Raw scores for Mathematics and Chitonga at the control and intervention schools.

\begin{tabular}{|c|c|c|c|c|c|c|c|c|}
\hline \multirow[t]{3}{*}{ Group } & \multicolumn{8}{|c|}{ Means and standard deviation } \\
\hline & \multicolumn{2}{|c|}{$\begin{array}{c}\text { Mathematics } \\
\text { pre-test }\end{array}$} & \multicolumn{2}{|c|}{$\begin{array}{c}\text { Mathematics } \\
\text { post-test }\end{array}$} & \multicolumn{2}{|c|}{$\begin{array}{l}\text { Chitonga } \\
\text { pre-test }\end{array}$} & \multicolumn{2}{|c|}{$\begin{array}{l}\text { Chitonga } \\
\text { post-test }\end{array}$} \\
\hline & $n$ & $\%$ & $n$ & $\%$ & $n$ & $\%$ & $n$ & $\%$ \\
\hline $\begin{array}{l}\text { Control } \\
(N=42)\end{array}$ & 8.2 & 3.30 & 8.4 & 2.58 & 10.3 & 3.26 & 9.4 & 4.31 \\
\hline $\begin{array}{l}\text { Intervention } \\
(N=42)\end{array}$ & 10.4 & 3.66 & 14.2 & 5.26 & 11.3 & 4.66 & 14.3 & 5.50 \\
\hline $\begin{array}{l}\text { Overall } \\
(N=84)\end{array}$ & 9.3 & 3.64 & 11.3 & 5.05 & 10.8 & 4.03 & 11.9 & 5.47 \\
\hline
\end{tabular}

TABLE 2: Independent samples $t$-test (pre- and post-test of both schools) for Chitonga.

\begin{tabular}{llccccc}
\hline Group & Test & Mean & SD & $\boldsymbol{t}$-test & df & $\boldsymbol{p}$ \\
\hline Control & Pre-test & 10.3 & 3.26 & -1.167 & 82 & 0.247 \\
Intervention & Post-test & 11.3 & 4.66 & - & - & - \\
Control & Pre-test & 9.4 & 4.31 & -4.487 & 82 & $0.001^{*}$ \\
Intervention & Post-test & 14.3 & 5.49 & - & - & - \\
\hline
\end{tabular}

SD, Standard deviation; df, degrees of freedom.

*, Significant at the 0.001 level.

TABLE 3: Independent samples $t$-test (pre- and post-test of both schools) for Mathematics.

\begin{tabular}{llccccc}
\hline Group & Test & Mean & SD & $\boldsymbol{t}$-test & df & $\boldsymbol{p}$ \\
\hline Control & Pre-test & 8.2 & 3.29 & -2.91 & 82 & $0.005^{*}$ \\
Intervention & Post-test & 10.4 & 3.66 & - & - & - \\
Control & Pre-test & 8.4 & 2.58 & -6.431 & 59.619 & $0.001^{* *}$ \\
Intervention & Post-test & 14.2 & 5.26 & - & - & - \\
\hline
\end{tabular}

$\mathrm{SD}$, Standard deviation; $\mathrm{df}$, degrees of freedom

*, Significant at the 0.05 level; **, Significant at the 0.01 level.

TABLE 4: Mean difference scores between the control and intervention schools in Mathematics and Chitonga.

\begin{tabular}{llcccccc}
\hline Test variable & School & Mean & SD & $\boldsymbol{t}$ & $\mathbf{F}$ & $\mathrm{df}$ & $\boldsymbol{p}$ \\
\hline Chitonga & Control & -0.9 & 3.3 & -4.6 & 4 & 82 & $0.048^{*}$ \\
performance & Intervention & 2.9 & 4.3 & - & - & - & - \\
Mathematics & Control & 0.19 & 2.4 & -5.1 & 14 & 82 & $0.001^{* *}$ \\
performance & Intervention & 3.8 & 4.00 & - & - & - & - \\
\hline
\end{tabular}

$\mathrm{SD}$, standard deviation; $\mathrm{df}$, degrees of freedom.

*, Significant at the 0.05 level; **, Significant at the 0.001 level.

girls $(\mathrm{M}=11.7, \mathrm{SD}=5.57)$ and boys $(\mathrm{M}=10.9, \mathrm{SD}=4.47)$, $(t[82]=0.763, p=0.448)$ were not significantly different.

An independent samples $t$-test was also used to assess differences in pre- and post-test scores between the control and intervention schools as shown in Table 2.

Mathematics mean scores for the control group were 8.21 and 8.40 (Table 3 ) in the pre-and post-test respectively and 11.33 and 14.26 for the intervention group. The results indicate a higher performance for the intervention group in the post-test.

Table 4 shows the mean scores on the two Grade 4 tests of the control and intervention groups. The results revealed that the intervention group gained a greater increase in mean scores than the control group. The results indicated a statistical significant difference in Chitonga $(t[82]-4.6, p=0.048,<0.05)$ and in Mathematics $(t[82]-5.1, p<0.001)$. This showed that there were statistically significant differences in scores in both subjects between the control and intervention groups.

To test if there were significant differences in the performance of students between the control and intervention schools, 
TABLE 5: Pearson product-moment correlation coefficients $(r)$ amongst test scores by learners in the control group at pre- and post-test stages.

\begin{tabular}{lccc}
\hline Subject & $\begin{array}{c}\text { Pre-test score } \\
\text { on Mathematics } \\
\text { test }\end{array}$ & $\begin{array}{c}\text { Post-test score } \\
\text { on Mathematics } \\
\text { test }\end{array}$ & $\begin{array}{c}\text { Post-test score on } \\
\text { Chitonga literacy } \\
\text { test }\end{array}$ \\
\hline $\begin{array}{l}\text { Baseline score on } \\
\text { Chitonga literacy test }\end{array}$ & $0.54^{* *}$ & $0.60^{* *}$ & $0.66^{* *}$ \\
$\begin{array}{l}\text { Baseline score on } \\
\text { Mathematics test }\end{array}$ & - & $0.69 * *$ & $0.31^{*}$ \\
\hline
\end{tabular}

*, Correlations significant at the 0.05 level; **, Correlations significant at the 0.01 level.

TABLE 6: Mann-Whitney $U$ test on parent-child interaction.

\begin{tabular}{lcccccc}
\hline Group & N & $\begin{array}{c}\text { Rank } \\
\text { average }\end{array}$ & $\begin{array}{c}\text { Sum of } \\
\text { ranks }\end{array}$ & U & Z & $p$ \\
\hline Control group & 42 & 28.70 & 1205.50 & 302.500 & -5.189 & $0.000^{*}$ \\
$\begin{array}{l}\text { Intervention } \\
\text { group }\end{array}$ & 42 & 56.30 & 2364.50 & - & - & - \\
\hline
\end{tabular}

*, Significant at the 0.001 level.

an ANOVA was conducted. The results showed greater gain in scores in the intervention school than the control school. The following were the results: Chitonga $(\mathrm{df}=1.82, \mathrm{~F}=21.229$, $p=0.001)$, Mathematics ( $\mathrm{df}=1.82, \mathrm{~F}=23.868, p=0.001)$. Therefore, we conclude that there were significant differences in the performance of students between the control and intervention schools in Chitonga and Mathematics.

To estimate the reliability of these tests, the product-moment correlations were computed amongst the scores by learners in the control group on each of the tests at baseline and at post-test stages (Table 5). The finding, that the two highest correlations were between the same tests at times 1 and 2, may be considered evidence of the reliability of the tests and their specificity.

In an attempt to identify processes mediating the impact of the intervention on the learning outcomes of children, a composite scale was constructed combining six items on the parent questionnaire that assessed the degree of parentchild interaction. Scores on this scale were computed from baseline and post-test responses by parents to form a score representing gains in the amount of supportive interaction experienced by each child. The mean of total supportive interaction scores at baseline were $(\mathrm{M}=19.88, \mathrm{SD}=7.74)$ and $(\mathrm{M}=20.98, \mathrm{SD}=3.75)$ for the control and intervention schools respectively. The post-test means were $(\mathrm{M}=22.3, \mathrm{SD}=3.83)$ for the control school and $(\mathrm{M}=22.9, \mathrm{SD}=3.20)$ for the intervention school. This supportive interaction difference score variable was treated as an ordinal scale. The MannWhitney U test (Table 6) was used to examine whether or not parents reporting larger increases in supportive interaction had children who showed larger performance gains on the academic tests, and this yielded a significant effect $(z=-5.189, p<0.05)$. The rank average for the control group was 28.70 (sum ranks 1205.50) while the intervention group scored a rank average of 56.30 (sum ranks 2364.50).

\section{Home-school communication}

In order to assess if there was a relationship between quality of home-school communication and academic performance of learners, changes in parental scores on the home-school communication scale between the baseline and post-test were computed. The mean scores for home-school communication for the control school were $(\mathrm{M}=9.8, \mathrm{SD}=2.07)$ and $(\mathrm{M}=10.6, \mathrm{SD}=2.09)$ for the intervention school. Correlation analysis found no significant relationship between changes in home-school communication and the academic performance of learners in Chitonga $(r=0.197$, $p=0.073)$ or in Mathematics $(r=0.039, p=0.725)$.

A Mann-Whitney $U$ test was used to assess whether or not there were significant differences in home-school communication at pre- and post-tests stages between the control and intervention schools. This showed a nonsignificant effect both at pre- and post-test stages $(\mathrm{z}=-0.111$, $p<0.05$ and $\mathrm{z}=0.581, p<0.05)$. The mean ranks for pre-tests were: control school 46.73 (sum of ranks 1962.50) and for the intervention school, 38.27 (sum of ranks 1607.50). The posttests showed the following mean rank results: control school 41.04 (sum of ranks 1723.50) while the intervention school indicated 43.96 (sum of ranks 1846.50).

\section{Qualitative data analysis}

After capturing qualitative data, the researcher read and re-read these in order to become familiar with them. In addition, two people were given the data to read. After this, the data were reviewed again with a view of identifying themes. The next step was to organise, code and interpret them.

\section{Parents' interviews and focus group discussion}

Local resources were used by parents in the intervention group to assist their children in Mathematics and Chitonga, including some found in the household and some in their immediate surroundings. Several parents reported discovering different materials other than those that were discussed in the workshop. When asked if parents found the workshop helpful, they acknowledged having gained knowledge from it, and that as a result they were better able to assist their children with school homework. When a middle-aged woman with secondary education was asked what she learnt from the workshop, she explained:

'Before the workshop I never knew that local resources can be used in helping children with schoolwork. Now I am able to remind my child that she can learn outside her classroom. The items we buy from shops have prints which my child uses to learn how to read or spell words. Empty plastic bags of sugar, salt and other items [are] used to practise weighing. For example, sugar is packed in kilograms, a bottle of cooking oil is measured in millilitres. I keep the containers and plastics as I buy commodities so that my child can use them for learning.' (Participant 21, female, business woman)

One of the old settlers with a large herd of cattle in the community was asked to comment on whether he learnt something from the workshop. He, likewise, agreed that the workshop had equipped him with knowledge about how to help his children with schoolwork. The study was conducted in an area where keeping animals is a widespread traditional practice. His response was: 
'I only knew that cattle are for labour, economic gains, food and "prestige" as per culture among Tonga people. Now I am able to teach my child how to count using different features of animals and these include ears, legs and other parts. When milking, my children use different containers for keeping milk.' (Participant 5 , male, farmer)

\section{Focus group discussion with Grade 4 learners}

A focus group discussion was held with learners at the intervention school. They were asked what challenges they had in doing homework. Selected quotations from the transcript are presented in the discussion section below to illustrate the challenges perceived by children at the uncertain intersection between their school curriculum homework assignments and the sociocultural context of their family life at home.

\section{Discussion}

The results reported above suggest that the strategy of our project was successful in attaining our intervention goal of generating synergistic collaboration between teachers and parents that combined to support children's development of cognitive competencies relevant to their local socioeconomic context. Grade 4 learners whose parents received the intervention improved their academic performance in Mathematics and Chitonga over the course of term 2 significantly more than learners at a very similar profile school who did not receive parental intervention. Moreover, as predicted, parents with children at the intervention school reported a significant increase in their involvement with their children regarding homework, while parents from the control school did not, suggesting that the improved academic performance of the children at the intervention school was mediated by increased parental involvement.

\section{Use of home resources}

Bronfenbrenner's (1979) ecological theory postulates that a child's cognitive development emerges from reciprocal interaction with parents as integral participants in the home microsystem. Accordingly, parents provide avenues in which their children can learn as they interact in their immediate everyday surroundings. The home environment is a rich source of easily accessible learning materials relevant to the cognitive domains of mathematics, language and literacy (Ng'asike 2014). Learners can benefit academically from this, provided that they recognise and understand connections between those home resources and the school curriculum, as they continue learning even during non-contact with their teachers. This creates an opportunity for them to understand more about what they have learnt at school.

During a focus group discussion with Grade 4 learners at the intervention school, they were asked what challenges they had in doing homework. A 12-year-old boy at the intervention school said:
'We don't have enough time to write homework because of gardening and herding animals. ... Parents tell us to carry our books as we go for herding animals and write while in the bush. ... During the day they say they are busy, at night they want to sleep.' (Participant 4, male, learner)

Such responses from parents to their children's requests for support may be attributed to a lack of knowledge on how to assist a child with schoolwork and failing to recognise socioeconomic benefits that schooling can bring about in the local community. Gardening is a cultural activity where a child can learn about the shapes in Mathematics like a triangle or a square. Calculations when vegetables are sold become a learning ground for the child. Using local resources to assist children with schoolwork requires little or no parental experience of formal schooling. Therefore, it is beneficial to sensitise parents to equip them with strategies on how to apply their own competencies to help their children. When learners are reminded to link outside or home activities to classroom situations, they will also be on the look-out to explore and tap into them for learning.

The intervention workshop mounted in this project sensitised parents to those connections by identifying household materials and domestic activities which could be incorporated in the primary school curriculum, and sought to motivate parents to deploy that understanding in the context of helping their children with homework assignments. Our findings suggest that this goal was achieved, narrowing the gap between the cultural practices of children's homes and schools, and generating significant gains in their academic learning.

\section{Increased home-school communication}

Parental perceptions of the quality of home-school communication was examined to explore whether or not it was a factor contributing to the improved academic performance of the children whose parents participated in the intervention. Communication between teachers and parents could be helpful to improve the learners' academic performance. Nevertheless, our data analysis found no significant relationship between parental reports on increased communication and the performance of children in Mathematics and Chitonga.

It is possible that the parents who responded effectively to the intervention by increasing the amount and quality of their interaction with their children relating to homework perceived the intervention as a uniquely helpful activity somewhat independent of their regular interactions with the school. In Musonda's (2011) study, both teachers and parents who were interviewed acknowledged that communication between home and the rural Zambian schools surveyed was very low and was largely through the participation of parents in parent-teacher association (PTA) meetings. Our questionnaire scale on communication considered the parents' attendance at PTA meetings and consulting teachers on how to assist their child. When one parent was questioned 
about communication between parents and the school, she stated that:

'Communication between parents and the school was quite good. Whenever I am needed teachers inform me in advance through writing notes or letters and give them to my children, though the common form of communication is when we are called for work on the school projects and PTA meetings. I have never been called to discuss the academic performance of my child or behaviour-related issues.' (Participant 32, female, farmer, longest standing PTA members)

Despite there being good communication between parents and the school, the focus of the communication was on improving the material resources and structures of the school. In the researcher's experience, in a few circumstances, children's performance is discussed in PTA meetings, but time allocation is usually restricted to talk about challenges faced by learners, or how they can progress.

In addition to the kind of hands-on assistance with their children's homework prompted in the present study, parents who value stronger home-school connections may offer support by encouraging older siblings and local neighbourhood peers to provide nurturant guidance to young learners. An intervention case study by Serpell, Mumba and Chansa-Kabali (2011) in a rural, Bembaspeaking district of Zambia's Northern Province, found that a Child-to-Child (CtC) curriculum that focused on health education, peer group cooperation, gender equality and helping others in the community was superior to the standard primary school curriculum, yielding higher academic performance and also generating more longlasting, socially responsible outcomes amongst learners.

Another, complementary type of intervention that enables families with limited print resources to facilitate early learning, in the domains of literacy and numeracy, deploys self-directed learning opportunities within a digital environment. For instance, a computer-based instructional phonics game (GrapohoGame), initially designed and validated by Heikki Lyytinen and his colleagues in Finland, provides support in learning letter-sound associations, a key aspect of initial literacy acquisition. The game has been translated into many different languages, mounted on hand-held mobile phones, and has been well received by urban and rural primary school learners and teachers in Zambia and several other countries of the Southern African Development Community (SADC) region (Ojanen et al. 2015). Nshimbi, Serpell and Westerholm (2020) found, in a rural community of Zambia's Eastern Province, that parents with minimal literacy who were loaned a smartphone with the game preloaded on it and shown by a local teacher how to operate it, were willing to allocate time for their children to play the game at home. This resulted in significant gains in the children's literacy acquisition. Moreover, a number of parents became engaged with playing the game themselves and made significant gains in literacy.

\section{Recommendations}

Taking the findings of this study in the context of other research, some recommendations may be formulated with the aim of encouraging the Ministry of General Education to come up with strategies of involving parents more actively in the education activities of their children. Without parents, the link between school, pupils and home becomes incomplete. A crucial precondition for such parent involvement in schooling in rural neighbourhoods is that a language of everyday discourse, familiar to the parents, should be integrated into the curriculum and teaching methods of local schools. Recent reforms in Zambia's national educational policy between 1998 and 2013 have gradually restored the principle of deploying indigenous local languages as the principal medium of instruction in the early grades. However, as Clemensen (2010) notes in her ethnographic study of children's educational experiences in Southern Province, the implementation of that principle has been fraught with anomalies informed by an underlying theme that learning in a local language is only a transitional phase along the way towards outcome competencies in English by the end of Grade 7.

Building a national consensus on the value of introducing children to initial literacy and Mathematics in the medium of a language with which they are already familiar (Government of Republic of Zambia [GRZ] 1996) has revealed widespread resistance, notably from the educated elite, based primarily in urban areas, whose economic privileges are widely perceived as being grounded in a superior command of English, the de facto language of power in the wider society (Kashoki 2018; Trudell 2016; Williams 2013). Yet in many rural areas (such as the Kalomo District), the overwhelming majority of parents share a single 'mother tongue' which can serve not only as an easier foundation for children's initial literacy learning, but also as a readily available medium of communication between their parents and teachers.

While the present study was based on a small sample, the findings were encouraging enough to warrant recommending that government's teacher training programmes include this type of focused attention on parental support for homework, as one way of mobilising local resources to assist children's learning. This and other instructionally focused topics on school-home cooperation are likely to be easier to promote, implement and foster the deployment of indigenous local languages in the context of the current policy, as a medium of instruction in the early grades, than it was during the extended period during which Zambia followed a policy of immersion of learners in English from Grade 1 onwards (Serpell 2018).

\section{Suggestions for further research}

Further research on parent-child interaction concerning homework could usefully include larger samples, comparisons between rural and urban schools, and the extension of the curriculum areas covered to other examinable subject areas, such as Social and Development Studies, Integrated Science, and Creative and Technology Studies. As recommended by 
Ishimaru, Barajas-Lopez and Bang (2015:14), the design of such studies should also seek to:

- engage families as knowers, doers, decision-makers and co-designers in the core work of disciplinary teaching and learning across contexts

- recognise and interrogate the complexity of family and community-based Mathematics knowledge embedded in cultural practices to expand disciplinary conceptions

- deepen understandings of families' and communities' roles in the development of students' academic, disciplinary and cultural identities.

\section{Conclusion}

This study was prompted by the recognition that despite a number of studies acknowledging the need for parental involvement to improve the academic performance of pupils, this has still remained low, especially in rural communities. This can be evidenced by a number of rural children who are unable to obtain assistance from their parents, resulting in the poor performance of pupils in Mathematics and Chitonga for the control group in the study. The study has shown that parents can be instrumental in the schooling of their children if they are adequately sensitised. This helped to increase the quality of parent-child interaction in homework as well as increase the use of home resources in the instruction of children in Chitonga and Mathematics, leading to better performance of pupils in the two subjects. Many parents in rural areas have insufficient knowledge about how to assist their children with schoolwork. Therefore, it is important to identify strategies that can help to engage parents to maximise their potential in helping their children.

\section{Acknowledgements}

The authors are grateful for technical support from the Examinations Council of Zambia in psychometric refinement of the academic performance measures developed in the study, and for the detailed, constructively critical feedback provided by anonymous reviewers engaged by the journal for evaluation of earlier drafts of the paper.

\section{Competing interests}

The authors have declared that no competing interests exist.

\section{Authors' contributions}

The research and writing of this article were performed by N.H.S. under the supervision of R.S.

\section{Funding information}

This research received no specific grant from any funding agency in the public, commercial or not-for-profit sectors.

\section{Data availability statement}

Readers interested in sharing access to the original data generated in this study should contact the corresponding author.

\section{Disclaimer}

The views and opinions expressed in this article are those of the authors and do not necessarily reflect the official policy or position of any affiliated agency of the authors.

\section{References}

Bronfenbrenner, U., 1979, The ecology of human development, Harvard University, Boston, MA.

Clemensen, N., 2010, 'Teaching in language limbo: Zambian primary teachers caught between policy and reality', in P. Cuvelier, T. du Plessis \& M. Meeuwis (eds.), Multilingualism from below: Studies in language policy in South Africa, pp. 35-36, Van Shaik Publishers, Pretoria.

Central Statistical Office (CSO), 2014, Southern province analytical report, CSO, Lusaka, Zambia.

Echaune, M., Ndiku, J.M. \& Sang, A., 2015, 'Parental involvement in homework and primary school academic performance in Kenya', Journal of Education and Practice 6(9), 46-53.

Epstein, J.L., 2001, 'Building bridges of home and school community: The importance of designs', Journal of Education for Students Placed at Risk 6(1), 61-68. https:// doi.org/10.1207/S15327671ESPR0601-2_10

Examinations Council of Zambia (ECZ), 2016, 2015 Examinations performance report General performance analysis, ECZ, Lusaka, Zambia.

Government of Republic of Zambia (GRZ), 1966, First National Development Plan, Office of National Development and Planning, Lusaka, Zambia.

Ho, C.L., 2007, 'Fostering parental involvement in children's Mathematics homework in Singapore pre-primary education: An intervention using parental education and school-home communication', Doctoral thesis, Durham University, Durham, UK. http://etheses.dur.ac.uk/2492

Hungi, N., 2011, Accounting for variations in the quality of primary school education, Southern and Eastern Africa Consortium for Monitoring Educational Quality viewed 10 January 2019, from https://www.sacmeq.org/sites/default/files/ sacmeq/reports/sacmeq-iii/working-papers/07_multivariate_final.pdf.

Ishimaru, A.M., Barajas-López, F. \& Bang, M., 2015, 'Centering family knowledge to develop children's empowered Mathematics identities', Journal of Family Diversity in Education 1(4), 1-21.

Kashoki, M.E., 2018, Nation building in the context of 'one Zambia one nation', Gadsden, Lusaka, Zambia.

Moll, L.C. \& Greenberg, J.B., 1990, 'Creating zones of possibilities: Combining social contexts for instruction', in L.C. Moll (ed.), Vygotsky and education: Instructional implications and applications of sociohistorical psychology, pp. 319-348, Cambridge University Press, New York, NY

Moll, L.C., Amanti, C., Neff, D. \& Gonzalez, N., 1992, 'Funds of knowledge for teaching: Using qualitative approach to connect homes and classrooms', Theory into Practice 31(1), 132-141. https://doi.org/10.1080/00405849209543534

Musonda, M.C., 2011, 'An investigation into parents' involvement in their children's education in selected rural schools in Central Province', Unpublished thesis, School of Education, University of Zambia, Lusaka, Zambia.

Ng'asike, J.T., 2014, 'African early childhood development curriculum and pedagogy for Turkana nomadic pastoralist communities of Kenya', in R. Serpell \& K. Marfo (eds.), Child development in Africa: Views from inside, New Directions for Child and Adolescent Development, vol. 146, pp. 43-60.

Ngwaru, J.M., 2014, 'Promoting children's sustainable access to early education in Africa: Reflections on the roles of parents on their children's early childhood care and education', New Directions for Child and Adolescent Development 24(146), 61-76. https://doi.org/10.1002/cad.20073

Nshimbi, C.J., Serpell, R. \& Westerholm, J. (2020). 'Using a phone-based learning tool as an instructional resource for initial literacy learning in rural African families', South African Journal of Childhood Education 10(1), 9. https://doi.org/10.4102/ sajce.v10i1.620

Nunes, T., Schliemann, A.D. \& Carraher, D.W., 1993, Street Mathematics and schoo Mathematics, Cambridge University Press, Cambridge.

Ojanen, E., Ronimus, M., Ahonen, T., Chansa-Kabali, T., February, P., Jere-Folotiya, J. et al., 2015, 'GraphoGame - A catalyst for multi-level promotion of literacy in diverse contexts', Frontiers in Psychology, 6, 671. https://doi.org/10.3389/fpsyg.2015.00671

Rogoff, B., Paradise, R., Arauz, R.M., Correa-Chávez, M. \& Angelillo, C., 2003, 'Firsthand learning through intent participation', Annual Review of Psychology 54(1), 175-203. https://doi.org/10.1146/annurev.psych.54.101601.145118

Seginer, R., 2006, 'Parents' educational involvement: A developmental ecology perspective', Parenting: Science and Practice 6(1), 1-48. https://doi.org/10.1207/ s15327922par0601_1

Serpell, R., 1993, The significance of schooling: Life journeys in an African society, Cambridge University Press, Cambridge.

Serpell, R., 1997, 'Critical issues literacy connections between school and home: How should we evaluate them?', Journal of Literacy Research 29(4), 587-616. https:// doi.org/10.1080/10862969709547975

Serpell, R., 1999, 'Local accountability to rural communities: A challenge for educational planning in Africa', in F. Leach \& A. Little (eds.), Education, cultures and economics: Dilemmas for development, pp. 107-135, Garland, New York, NY. 
Serpell, R., 2018, 'Application of research evidence in policy formulation to enhance child development opportunities in Zambia', in S. Verma \& A. Petersen (eds.),
Developmental science and sustainable development goals for children and youth, Developmental science and sustainable development goals for children and youth,
pp. 375-388, Springer, New York: Springer International Publishing, viewed 04 pp. 375-388, Springer, New York: Springer International Publishing, viewed 04
February 2019, from https://www.springer.com/us/book/9783319965918. February 2019, from https:

Serpell, R. \& Marfo, K., 2014, 'Some growth points in African child development research', in R. Serpell \& K. Marfo (eds.), Child development in Africa: Views from
inside, New Directions for Child and Adolescent Development, vol. 146, pp. 97inside, New Directions for Child and Adolescent Develop
112. https://doi.org/10.1002/cad.2014.2014.issue-146

Serpell, R., Mumba, P. \& Chansa-Kabali, T., 2011, 'Early educational foundations for the development of civic responsibility: An African experience', in C.A. Flanagan \& B.D. Christens (eds.), Youth civic development: Work at the cutting edge, New Directions for Child and Adolescent Development, London, vol. 134, pp. 77-93, viewed 04 May 2015, from www.childtochild.org.uk.
Simweleba, N.H., 2017, 'The influence of parental involvement on Maths and literacy and the academic performance of pupils: A case of selected schools in Kalome District, Zambia', MA thesis, Department of Psychology, University of Zambia, District, Zambia,
Lusaka, Zambia.

Trudell, B., 2016, 'Language choice and education quality in Eastern and Southern Africa: A review', Comparative Education 52(3), 281-293. https://doi.org/10.1080 /03050068.2016.1185252

Williams, E., 2013, 'Political perspectives on language policies and development in Africa', in E.J. Erling \& P. Seargeant (eds.), English and development: Policy, pedagogy and globalization, vol. 17, pp. 68-87, Multilingual Matters, Bristol.

Yoshikawa, H., Weisner, T.S., Kalil, A. \& Way, N., 2008, 'Mixing qualitative and quantitative research in developmental science: Uses and methodological choices', Developmental Psychology 44(2), 344-354. https://doi.org/10.1037/ 0012-1649.44.2.344 


\section{Appendix 1: Teacher-parent activities for improving learner performance (a) Homework}

The use of homework that requires parent-child interaction can create a line of communication between parents and teachers, increase family involvement and help improve student achievement.

\section{(b) Communication}

- Through effective communication with parents, teachers can have the greatest impact on their day-to-day success with students.

- With parents on their side, teachers can more effectively manage most academic and behavioural issues that arise. When the most important adults in a child's life are working together, students benefit enormously.

- What form of communication works best for you?

1. Telephone?

2. Note/letter?

3. Face-to-face?

4. Other?

- What kinds of information do you most want to receive from the school?

- What might the school do differently to improve communication between school and home?

- What might you do differently to improve communication between home and school?

\section{Group activity/discussion triggers}

- Do you know the name(s) of your child's teacher(s)?

- Do you know the best way and time to contact your child's teacher(s)?

- Does your child's teacher know the best way to contact you?

- What are three things you would like to know from the teacher so that you can better help your child?

- What are three things you would like for the teacher to know about your child so he/she can better help your child?

\section{Four things parents wish teachers knew}

1. Encourage parent participation by reaching out to involve parents in their children's education. Show parents how they can help their children at home. Understand that parents want to work with teachers to help their children be successful.

2. Regularly assign homework that helps children learn, and advise parents about how they can work with their children on their homework.

3. Communicate often and openly with parents, contacting them early about academic or behavioural problems, being candid rather than defensive when discussing these problems.

4. Set high academic standards, expecting all students to learn and helping them to do so.

\section{Things teachers wish parents would do}

1. Be involved in their children's education. Parent involvement helps students learn, improves schools and makes teachers' jobs easier.

2. Provide resources at home for reading and learning. Parents should have books and magazines for their children and read with their children each day.

3. Set a good example. Parents should show their children that they believe reading is enjoyable and useful.

4. Encourage children to do their best in school. Parents should encourage children to do their best, and children should be helped to set obtainable goals.

5. Academics should be a primary concern, followed by their children's preparation for the world of work and involvement in athletics and activities.

6. Support school rules and goals. Parents should take care not to undermine school rules, discipline or goals.

7. Use pressure positively. Parents should gently urge their children to attempt new activities but they should not apply too much pressure by involving them in too many activities.

8. Call teachers as soon as a problem becomes apparent so that timely action can be taken.

9. Exercise parental responsibility and do not expect the school and teachers to take over this job. For example, teaching necessary discipline is a parental rather than a school responsibility. 


\section{Trainer narrative}

- The checklists identify critical information parents and families need to know. Therefore parents need the opportunity to communicate with teachers, ask questions, and provide input so that they can work together more effectively.

- The checklist implies that the school is responsible for providing information to parents in a timely manner and in a language and format they can understand.

- Parents also should take the initiative to contact the teacher, ask questions, and receive relevant information that will help them help their child.

- Allow the participants' time to review the checklists and to ask questions about the checklists. Encourage the participants to offer suggestions about items to be added (or edited) in the checklist.

\section{(c) Learning at home}

The most effective forms of parent involvement are those which engage parents in working directly with their children on learning activities in the home (Ho, 2007).

\section{As a parent involved in your child's education, you: \\ At home}

- Send your child to school every day, well rested and fed, with a positive comment about him/her.

- Take an active interest in your child's schooling and let your child know how much you care about learning.

Find out what happened at school each day and how your child felt about it.

- Learn as much as you can about being an effective parent.

- Try not to let any negative experiences keep you from supporting and encouraging your child's education.

- Try to provide a variety of interesting reading materials in your home and spend time reading and writing with your child.

- Provide an area in your home where your child can keep her/his school things and, if possible, where she/he can do schoolwork without continual interruption.

Find ways to involve the family in homework or similar activities and remain supportive of the child's need to do homework.

- Show pride in your child's work and display it in special places in your home.

- Follow up with your child and monitor homework and be consistent in your expectations.

- As appropriate, work with your child on school-related projects on a regular basis.

- Include your child in daily household tasks and make the connection between learning in school and application in daily life.

\section{(d) Home resources}

\section{Main points to be communicated}

- Homes are a rich source of learning materials especially when parents are sensitised on how to utilise them.

- Parents can assist in their children's learning using different resources in their homes.

- Parents can also engage their children in mathematical talks - discussions about shapes, size, patterns, grocery list, etc.

\section{Ice breaker}

Through using home resources, parents can be better teachers of their children. Effective learning will continue taking place after school hours. When this happens, students make great connections between what happens at home and at school, hence they benefit enormously.

\section{Group activity/discussion}

- In groups, parents write down five things that can be used to teach children at home.

- Teachers write five things they think parents can use at home to assist their children in education activities.

- (Pots, cups, buckets, bags, bottles of cooking oil, different containers, spoons, different types of domestic animal, etc.).

\section{Activities in the home}

Parents can do different activities with their children in homes:

- They are their children's first teachers.

- Children do not only learn at school.

- They can easily be helped at home. 


\section{Ways children can be assisted at home}

Do things together with your child.

- Cooking; measuring, weighing, etc.

- Shopping; talk about weight, quantity, size, price, total cost, etc.

- Playing in sand and water; filling different containers with sand or water.

- Field work; seeing different bags of fertilizer and seed, counting different farm products.

- Stories; telling children different stories.

\section{For teachers}

- Teachers in schools where parents and families are actively involved find that their jobs become much easier. Working in partnership with students and parents creates an environment of trust, positive interaction and optimism for what can be accomplished.

- Having the support of parents relieves considerable stress for teachers who often feel they are struggling alone to improve children's academic options.

- Effective parent involvement programmes can prevent burnout and the loss of hardworking, dedicated teachers.

- Teachers are a pivotal link in establishing and maintaining solid parent involvement efforts. Without teachers who are actively committed to encouraging parents in the important roles they can play, schools will have a difficult time recruiting parents and keeping them involved. 